\title{
Stress hormone level and the welfare of captive European bison (Bison bonasus): the effects of visitor pressure and the social structure of herds
}

Daniel Klich ${ }^{{ }^{*}} \mathbb{D}$, Rafał Łopucki ${ }^{2}$, Marta Gałązka ${ }^{1,3,4}$, Agnieszka Ścibior ${ }^{5}$, Dorota Gołębiowska ${ }^{5}$, Rita Brzezińska ${ }^{6}$, Bartosz Kruszewski ${ }^{7}$, Tadeusz Kaleta ${ }^{1}$ and Wanda Olech ${ }^{1}$

\begin{abstract}
Background: Captive European bison (Bison bonasus) play an active role in conservation measures for this species; this includes education, which may conflict with these animals' welfare. The effect of the presence of visitors on the welfare of captive animals can be negative, positive or neutral. However, the response of a given species to visitors is difficult to predict, since even closely related species display varying levels of tolerance to captivity. The aim of the study was to compare immunoreactive fecal cortisol levels (regarded as an indicator of the level of physiological stress) in groups of captive European bison that differed in terms of their social structure and the level of visitor pressure. The second aim was to determine if there was a correlation between intestinal parasitic burden and immunoreactive fecal cortisol levels.
\end{abstract}

Results: Immunoreactive fecal cortisol levels were not influenced by sex or age. However, study site and the interaction between study site and visitor pressure were statistically significant. European bison in one enclosure presented higher levels of immunoreactive fecal cortisol on weekdays than at weekends. In the other two study sites, the levels did not differ between weekdays and weekends. No correlation was found between parasitological infestation and immunoreactive fecal cortisol levels.

Conclusions: Measurement of fecal cortisol metabolites could be a valuable method for further research into the welfare of European bison in captivity. More subtle factors such as individual animal characteristics, feeding systems, and the arrangement of enclosures can be of great importance in terms of the effect of visitors on animals. The results of this study can be used in guidelines for the management of European bison populations.

Keywords: Aggression, Cortisol, Enclosure, Wisent, Parasitological infestation, Zoo, Feces

*Correspondence: daniel_klich@sggw.edu.pl

1 Department of Animal Genetics and Conservation, Institute

of Animal Sciences, Warsaw University of Life Sciences, Ciszewskiego 8, 02-786 Warsaw, Poland

Full list of author information is available at the end of the article

\section{Background}

Breeding of captive European bison (Bison bonasus) saved this species, which was extinct in the wild in 1919 [1]. As a result of conservation efforts, the wild population of European bison has spread across a large area of Europe [2, 3]. However, a significant proportion of the entire European bison population is made up of animals that are kept in captivity, therefore protecting these

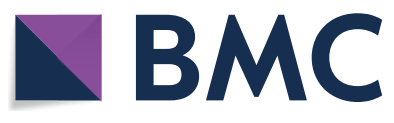

(c) The Author(s) 2021. This article is licensed under a Creative Commons Attribution 4.0 International License, which permits use, sharing, adaptation, distribution and reproduction in any medium or format, as long as you give appropriate credit to the original author(s) and the source, provide a link to the Creative Commons licence, and indicate if changes were made. The images or other third party material in this article are included in the article's Creative Commons licence, unless indicated otherwise in a credit line to the material. If material is not included in the article's Creative Commons licence and your intended use is not permitted by statutory regulation or exceeds the permitted use, you will need to obtain permission directly from the copyright holder. To view a copy of this licence, visit http://creativeco mmons.org/licenses/by/4.0/. The Creative Commons Public Domain Dedication waiver (http://creativecommons.org/publicdomain/ zero/1.0/) applies to the data made available in this article, unless otherwise stated in a credit line to the data. 
animals is also an important element of conservation strategies [4]. For this reason, methods of European bison breeding are constantly the subject of scientific considerations $[5,6]$. Captive breeding allows individual mating to be planned, initial herds to be created, wild populations to be enriched with individuals of known origin (e.g., to increase the genetic diversity of free-ranging herds), and research to be conducted on the health of European bison [7-10]. Keeping animals in enclosures allows them to be presented to the public, which in turn may contribute to increased acceptance of the occurrence of wild herds in natural environments [11]. This educational role is realized by zoos and breeding farms, where European bison are presented in a quasi-natural environment. These centers are popular tourist attractions because the European bison is the largest mammal species in Europe and is deeply embedded in culture and art $[12,13]$.

The educational aspects of presenting captive European bison may, however, conflict with its welfare due to the almost permanent presence of visitors. The effect of visitors on the stress and welfare of exhibited animals has been shown for many captive species $[14,15]$. However, the response of a given species to visitors is difficult to predict, since even closely related species show varying levels of tolerance to captivity [16]. Theoretically, the effect of the presence of visitors on captive animals' welfare could be negative (e.g., stress-inducing), positive (as a kind of enrichment) or neutral; however, descriptions of negative effects dominate in the literature. Morgan and Tromborg [17] and Sade [18] noted that there are several sources of stress that are typical of captive animals, and a cumulative effect of stressors related to visitors can occur, e.g., the cumulative effect of the number of visitors, their behavior, the closeness of interaction with animals, and the noise produced. Detailed studies on the relations between visitors and animals kept in enclosures have mainly concerned primates and have revealed increased frequency of abnormal behavior, increased cortisol levels, or altered behavior as a result of visitor pressure [15, 19]. A negative reaction to visitor pressure was also often the case with captive ungulates, including social species [20-23]. On the other hand, observation of 12 species of ruminants in captivity showed only a slight reaction to visitors, but for some species this reaction depended on the sex of the animals [24].

The positive role of visitors in terms of their function as enrichment for captive animals is still being discussed in behavioral research $[14,15]$. There are several species whose high level of curiosity leads them to approach visitors frequently. A particularly interesting case is the black-tailed prairie dog (Cynomys ludvicianus), which displays stronger positive reactions (adults kiss more and fight each other less) when there is a greater number of visitors [25]. Wood [26] observed positive changes in behavior in a group of captive chimpanzees (Pan troglodytes), and Owen [27] observed that play behavior was stimulated by visitors in the Asian short-clawed otter (Aonyx cinerea).

On the basis of the present research, it is difficult to predict the physiological response of European bison to the pressure of visitors and to find the right compromise between educational goals and the welfare of this species in captivity. It should be remembered that European bison naturally live in groups, therefore social relations are an important factor that affects the broadly understood welfare of this species [28]. In wild herds of European bison, an adult female has the role of group leader; however, some studies indicate collective decision-making [29], whereas aggression is usually associated with males [30,31]. These behavioral features are usually taken into consideration when evaluating breeding strategies, and the general rule in captive herds is to keep one adult male in a family group to minimize aggression, especially between males. When these rules are not complied with, one extreme effect of adult male aggression is the killing of a young individual in the enclosure. For this reason, subadult males are transferred to other breeding centers or kept isolated [5].

The aim of the study was to compare immunoreactive fecal cortisol levels as they are an indicator of physiological stress levels in groups of captive European bison with varying social compositions and levels of visitor pressure. Knowledge on the social relations of the European bison was applied and the research was intentionally conducted in captive herds with a herd structure that was potentially conflictive or non-conflictive. The presence within the herd of a subadult male (i.e., about 3 years old) that could challenge older males was assumed to be a source of social conflicts. The hypothesis was formulated that social relations in a group of animals kept in captivity could be affected by visitor pressure and that this phenomenon would occur most in groups in which social conflicts (disorders) arise. Fecal glucocorticoid metabolite analyses are increasingly used in a variety of studies to examine stress hormone secretion in domestic and wild vertebrates [32,33]. Moreover, when studying the impact of visitors on captive animals, this method is simple and promising, especially since the results of traditional behavioral observation studies may be less unequivocal [34].

The second aim was to determine if there is a correlation between intestinal parasitic burden and immunoreactive fecal cortisol levels. European bison are regularly dewormed at breeding centers, but their levels of parasitism can fluctuate greatly and even exceed the levels found in wild herds [35]. Although current research indicates a 
possible relation between parasitological infestation and the stress level of animals [36,37], such studies have not yet been carried out on the European bison.

Over the last 100 years, the parasitic fauna of European bison has been thoroughly examined, and it is known that the most common parasites are nematodes from the Trichostrongylidae family, e.g., Ostertagia ostertagi, Ostertagia leptospicularis, Ostertagia kolchida, nematodes from the Trichuris genus, and coccidia from the Eimeria genus [38, 39].

\section{Methods}

\section{Animals and study sites}

When selecting the study sites, the following criteria were taken into account: (1) the studied herds of European bison should be family-like groups consisting of an adult male, adult females, and young individuals of both sexes; (2) groups should be characterized by varied social structures (based on interviews with animal keepers, captive herds with potentially conflictive or non-conflictive social structures were selected); (3) study sites should be characterized by cyclically variable visitor pressure (a greater number of visitors at weekends compared to weekdays); and (4) the enclosure layout and herd structure should ensure the possibility of taking fecal samples from identified individuals.

To simplify counting the number of visitors, daily ticket sales were analyzed. While this does not indicate whether a person actually visited the European bison enclosure, the number of tickets sold objectively indicates the trend in the number of visitors on weekdays and at weekends, and such trends are enough to reflect the level of visitors. After considering these factors and obtaining permits from administrators, the following locations were selected for the study: the zoos in Poznan and Warsaw, and the Forest Culture Center (FCC) in Gołuchów.

In these locations, animals were kept in typical group structures with one adult male, a few adult females, and young animals of both sexes (Table 1). However, in Warsaw Zoo and FCC Gołuchów, the herds also included a subadult male aged about 3 years. The three locations differed in terms of enclosure size and visitor numbers, and as a consequence the animal density per ha varied (Table 1). In FCC Gołuchów, European bison were allowed to use a 20 ha enclosure, but it was separated into two main pens: a daily pen of about 1 ha, where the animals were exposed to visitors, and a nighttime pen that was open to the animals at night. Visitor numbers significantly differed between working days and weekends: at weekends, there were 5-7 times more visitors (Table 1). On weekdays, there were no events that could affect the animals' stress levels or unintentionally increase the number of visitors. The diet of the European bison differed between the locations (Table 2): cereals or a commercial fodder mixture were the basis of European bison's diet. At FCC Gołuchów and Warsaw Zoo, the fodder was more diverse and was supplemented with natural plant food. In all locations, hay or haylage was offered ad libitum.

The enclosures were arranged in various ways (Fig. 1). In Warsaw Zoo, the enclosure was accessible to visitors from three sides, but fodder was given away from the view of visitors behind a concrete wall and an artificial hill. However, visitors could view animals feeding on hay near a viewpoint. In Poznań Zoo, the enclosure was surrounded by trees, but a viewpoint allowed good observation of the whole enclosure. Fodder was served in front of the viewpoint. At FCC Gołuchów, visitors had access to

Table 2 Composition of European bison diet in individual locations in winter and early spring (kg per adult individual)

\begin{tabular}{llll}
\hline Fodder & Poznań zoo & Warsaw zoo & FCC Gołuchów \\
\hline Cereals & 0.5 & 0.4 & 4.5 \\
$\begin{array}{l}\text { Commercial fodder } \\
\quad \text { mixture for livestock or }\end{array}$ & 2 & 0.8 & - \\
$\quad \begin{array}{l}\text { European bison } \\
\text { Root crops }\end{array}$ & - & 1.5 & 7.5 \\
Seeds of trees & - & 0.2 & 1 \\
Leaves/branches & - & 0.5 & addition \\
Hay & ad libitum & ad libitum & 4.5 \\
Haylage & - & - & ad libitum \\
\hline
\end{tabular}

Table 1 Composition of the European bison breeding group and enclosure conditions in each location ( ${ }^{*}$ during daytime, a pen of about 1 ha is available for the animals)

\begin{tabular}{|c|c|c|c|c|c|c|}
\hline \multirow[t]{2}{*}{ Location } & \multirow[t]{2}{*}{$\begin{array}{l}\text { Area of } \\
\text { enclosure (ha) }\end{array}$} & \multirow[t]{2}{*}{ Females (years old) } & \multirow[t]{2}{*}{ Males (years old) } & \multirow[t]{2}{*}{ Animals per ha } & \multicolumn{2}{|c|}{$\begin{array}{l}\text { Mean Visitor numbers } \\
\text { (persons/day) }\end{array}$} \\
\hline & & & & & Weekdays & Weekends \\
\hline Poznań zoo & 0.5 & $10,8,1.5$ & $12,1.5$ & 10 & 19.5 & 99 \\
\hline Warsaw zoo & 0.3 & $9,9,3,2,1,0.5$ & 11,3 & 26.7 & 196.3 & 1087.5 \\
\hline FCC Gołuchów & $20^{*}$ & $11,11,2$ & $11,3,1,1$ & 0.35 & 90 & 650 \\
\hline
\end{tabular}




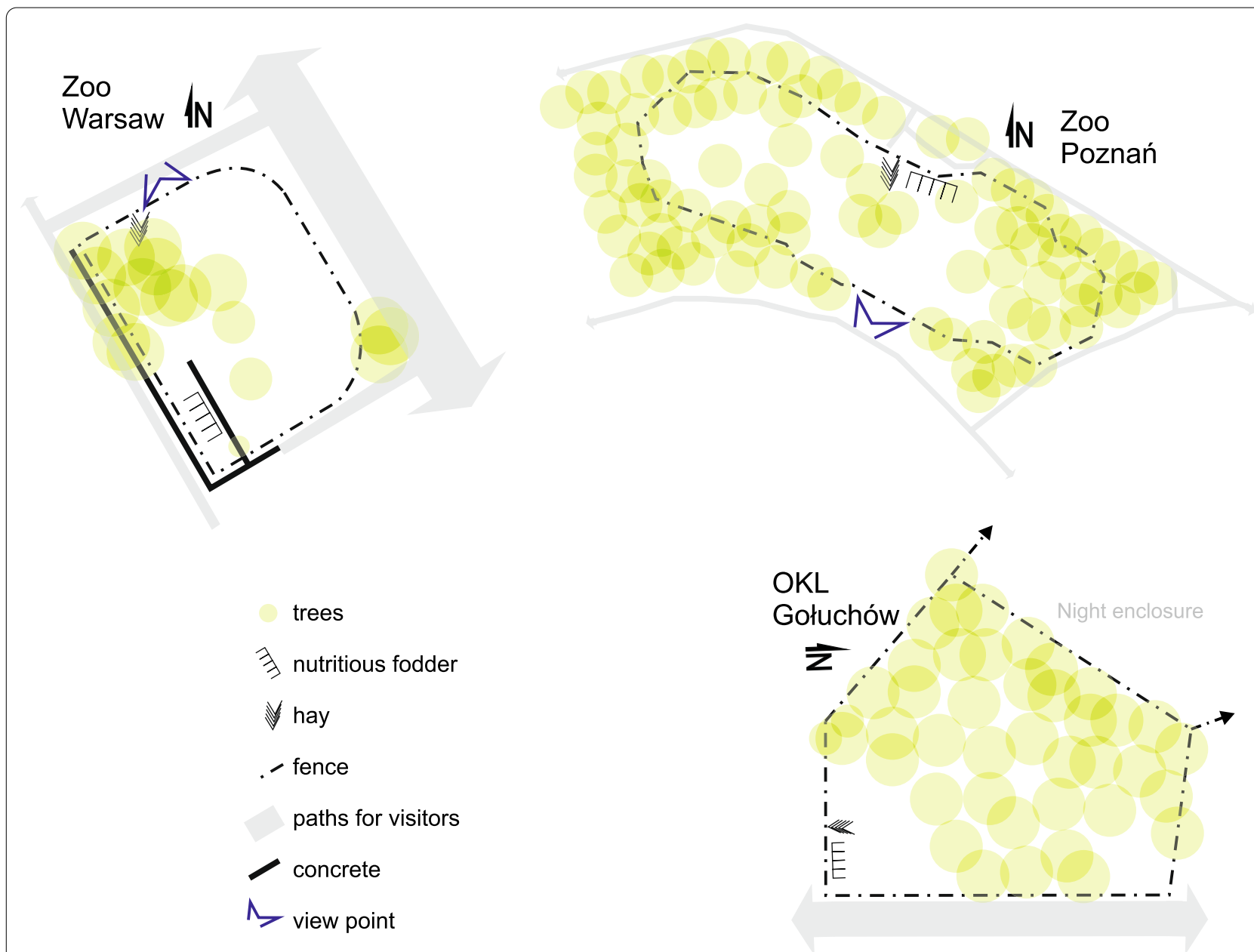

Fig. 1 Maps of European bison enclosures in the three study sites. For FCC Gołuchów, only the daytime enclosure is presented

the enclosure from one side. The area was covered with trees, but these did not affect the visitors' view. Feeders for these bison were located right next to the visitors' path (Fig. 2). Visitors at Warsaw Zoo could observe animals from a height of about $2.5 \mathrm{~m}$; at FCC Gołuchów this was about $1 \mathrm{~m}$, but at Poznań Zoo visitors and bison were at the same height. In both zoos, animals were given nutritious fodder only once a day at about $8 \mathrm{am}$, before visitor facilities were open. At FCC Gołuchów, animals were given fodder twice a day: at 8 am and at about $4-5 \mathrm{pm})$.

\section{Study design}

Samples were collected during the mild winter (December to February) in 2019-2020. Collection during this period allowed higher ambient temperatures and the reproductive period to be avoided, both of which could affect the level of immunoreactive fecal cortisol in animals [40-42]. The ambient temperature during material collection in the study ranged between 4 and $12{ }^{\circ} \mathrm{C}$.
Fecal samples were collected for 5 consecutive days from Friday to Tuesday, except for the zoo in Poznań, where collection took place over 4 days (Saturday-Tuesday). Each day, samples were collected in the morning by animal keepers. Based on direct observation of the animals, each sample was assigned to the relevant individual, whose age and sex were known. Samples $(2 \mathrm{~mL}$, taken from the central part of the bolus) were frozen at $-20{ }^{\circ} \mathrm{C}$, transported to the laboratory, and stored at the same temperature until the immunoreactive fecal cortisol level analysis. An additional $50 \mathrm{~mL}$ of feces was collected at Warsaw Zoo to assess parasitological infestation. These samples were cooled to $6{ }^{\circ} \mathrm{C}$ and stored until analysis. In total, 80 samples were collected from 19 animals for immunoreactive fecal cortisol analysis, and 33 samples were collected from 7 animals for assessment of parasitological infestation.

The level of immunoreactive fecal cortisol in the samples was measured using a non-specific commercial ELISA kit (COR ELISA Kit No. EU0391, competitive 

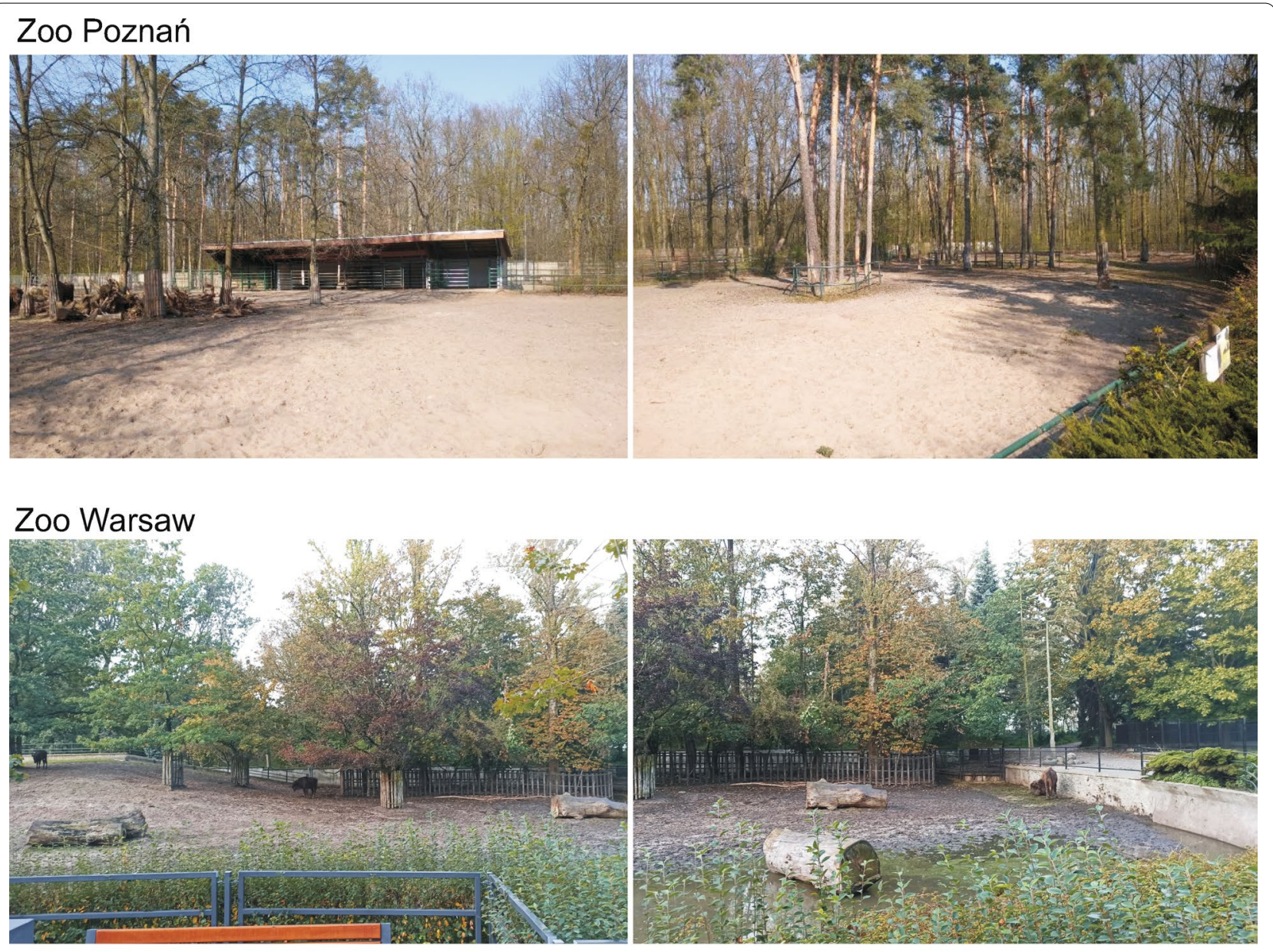

\section{FCC Gołuchów}

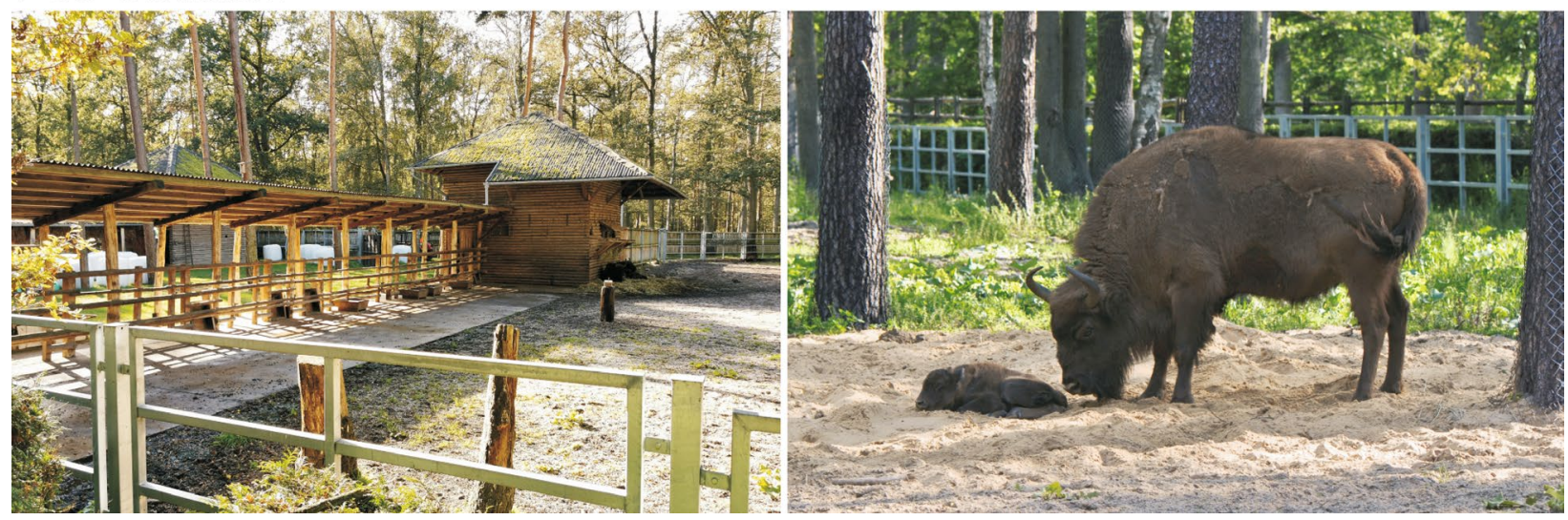

Fig. 2 Photographic presentation of European bison enclosures in the three study sites

variant, Wuhan Fine Biological Technology Co., China). All details concerning the methodology of determining immunoreactive fecal cortisol have been described previously [43]. The analysis was performed using a Synergy 2 microplate reader* (BioTek Instruments, Inc.
Winooski, Vermont, USA) equipped with an automated microplate strip washer* (ELx50, BioTek Instruments, Inc.) and an ELMI DTS-4 4-plate microplate thermo shaker* (ELMI SIA, Riga, Lithuania). All 80 samples were located within the range of the standard curve. 
Intra- and inter-assay coefficients of variation were $10.6 \%$ and $12.8 \%$, respectively. Immunoreactive fecal cortisol levels were expressed as nanograms per one gram of dry mass of feces (ng/g). $1 \mathrm{~g}$ of fresh feces from each sample was weighed (with precision $0.001 \mathrm{~g}$ ), dried at $60{ }^{\circ} \mathrm{C}$ for $24 \mathrm{~h}$, and then weighed again (with the same precision) to assess the water content in each sample.

The commercial ELISA kit was biologically validated for the European bison using samples from three males that were transported from Poland to Spain. Two of the animals, named Plener III and Platyn, were taken from Pszczyna Park enclosure; one, named Podlas, was taken from FCC Gołuchów. The animals were transported in November to Encinarejo in Spain. The animals were 2-4 years old. In Pszczyna Park enclosure, no herd manipulations were carried out prior to transport. In FCC Gołuchów, Podlas was separated from the herd before transportation due to male aggression in the main enclosure. Before and after transportation, fecal samples were collected from all three animals. As the collection of fresh samples from European bison is difficult, sampling was carried out over several weeks. Finally, eight samples were collected from each individual and analyzed. We assumed that pre-transport sampling would provide information on the levels of immunoreactive fecal cortisol in the animals in their original environment. After transportation, however, efforts were made to collect samples in the first few days after the animals arrived. Samples were frozen at $-20{ }^{\circ} \mathrm{C}$ immediately after collection; they were then transported to the laboratory and stored at the same temperature until analysis. The experiment required the transport of samples from Spain to Poland in a transportable freezer at $-20{ }^{\circ} \mathrm{C}$. The immunoreactive fecal levels were compared before and after the transport.

All animals showed an increase in immunoreactive fecal cortisol level in fecal samples after transportation.
Compared to the mean values before the transport, the level increased from 8 to 33 times on the first day after transport (Fig. 3). Compared to the pre-transport period, on the next 2 days (day 2 and 3) mean immunoreactive fecal cortisol levels in the fecal samples was 4.6 and 7 times higher for Plener III and Platyn, respectively (Fig. 3a, b). For Podlas, this value could not be determined because the material was not collected on the second day (Fig. 3c); this animal was separated from the herd before transportation and had already displayed increased immunoreactive fecal cortisol level in the pre-transport period. We were not able to statistically compare the immunoreactive fecal cortisol levels in the pre-transport and post-transport periods $(n=8$ for each animal) because of the small sample size.

Three grams from each sample were examined for the presence of the eggs of gastrointestinal nematodes, and oocysts of coccidia from the genus Eimeria using McMaster's quantitative method [44] in sucrose solution $(\mathrm{SG}=1.27)$ [45]. The McMaster method can detect as few as 50 helminth eggs per gram of feces (EPG) and 50 Eimeria oocysts per gram of feces (OPG). Direct flotation was performed to identify the oocysts; their length and width were measured, and their morphology was analyzed. Descriptions of oocyst morphology and species differentiation followed the guidelines of Duszynski and Wilber [46] and Pyziel et al. [35, 38]. Samples were investigated using an OPTA-TECH Lab 40 light microscope at $\times 100$ magnification for the McMaster method and $\times 100-400$ magnification for direct flotation.

\section{Data processing and statistics}

Sampling days were divided into two groups according to visitor pressure: low visitor pressure on weekdays and elevated pressure at weekends. When analyzing the data, it was considered that glucocorticoids, which are secreted into the blood, are excreted via the feces (in
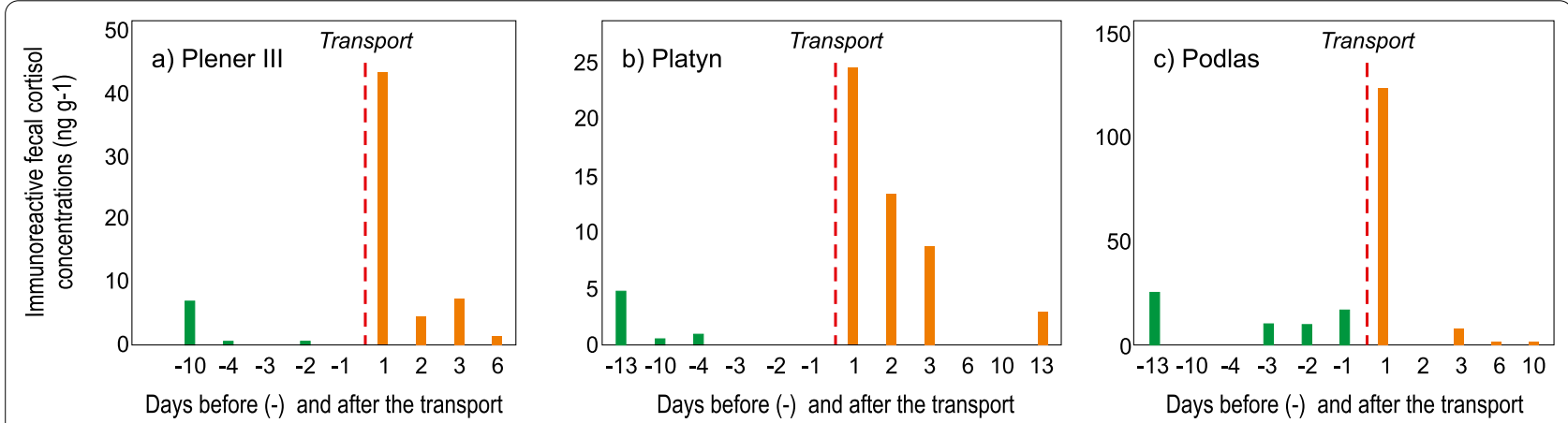

Fig. 3 Immunoreactive fecal cortisol levels for samples collected from the three European bison bulls on the days before (marked as "-") and after transport: a Plener III, b Platyn and c Podlas 
the form of fecal cortisol metabolites) after a delay. For livestock, this delay is about 10 to $24 \mathrm{~h}$ [33, 47, 48]. For this reason, because the samples were collected on consecutive days, the immunoreactive fecal cortisol level detected in a given sample represented the animal's stress level on the previous day.

To assess the relation between immunoreactive fecal cortisol and parasitic burden, two dominant groups were used: Eimeria sp. and Trichuris sp. The relation was analyzed in two ways: directly (eggs or oocysts from the same fecal sample as the immunoreactive fecal cortisol level) and shifted days (comparison of eggs or oocysts against the fecal sample from the same animal on the next day). The direct relation (fecal samples from the same day) indicated the impact of the level of stress on egg/oocyst shedding (because glucocorticoids are evident in feces after a delay and thus represent the stress level for the previous day); the shifted comparison (eggs or oocysts counted in feces on the next day) indicated the impact of egg/oocyst shedding on immunoreactive fecal cortisol level.

Statistical analyses were performed in SPSS software. To reach normality, the response variable was Box-Cox transformed. The analysis of visitor impact at the selected locations was carried out with a general linear mixed model in which the immunoreactive fecal cortisol level was analyzed (as a dependent variable) with regard to four explanatory variables: (a) location (Poznań, Warsaw or Gołuchów); (b) visitor pressure (low and elevated number of visitors); (c) age of the animal; and (d) sex of the animal. We also added interactions between visitor pressure and all other variables: location, age and sex. In the model, the levels (weekdays and weekends) of visitors were used instead of the actual number of visitors. Because the conditions in the enclosures were not comparable, a similar number of visitors could impact these enclosures differently. Animal ID number was fitted as a random effect to account for the repeated sampling of individual animals. Restricted maximum likelihood (REML) was used to estimate the parameters in the best model obtained. Model selection was based on Akaike information criterion (AIC) values in a multi-model selection procedure [49]. All possible model permutations with all the explanatory variables were performed; finally, the models were ranked according to their Akaike weights (Additional file 1: Table S1). The principle of model selection was lower AIC values, but when the difference between the models was less than $\mathrm{AIC}=2$, the simpler model was chosen. A pairwise comparison with least significant difference (LSD) of groups was used in the factors that were statistically significant in the model. Analysis of the relation between parasitological infestation and immunoreactive fecal cortisol level was performed with Pearson's correlation coefficient $(\mathrm{r}, \mathrm{n}=33$ for direct comparison and $\mathrm{n}=25$ for shifted comparison).

\section{Results}

Immunoreactive fecal cortisol levels were not influenced by sex, age, or visitor pressure $(\mathrm{P}>0.05$; Table 3$)$. However, study site and the interaction between study site and visitor pressure were statistically significant $(P<0.05)$. European bison in Gołuchów presented higher levels of immunoreactive fecal cortisol on weekdays than at weekends $(\mathrm{P}<0.001$; Fig. 4). Immunoreactive fecal cortisol levels of European bison housed in Poznań Zoo and Warsaw Zoo did not differ between weekdays and weekends $(\mathrm{P}=0.972$ and $\mathrm{P}=0.943$, respectively). At weekends, levels were higher in Warsaw Zoo than in Gołuchów $(\mathrm{P}=0.022)$.

Parasitological examination showed the presence of eggs of gastrointestinal nematodes from the Trichostrongylidae family, nematodes from the Trichuris genus, and oocysts of five species of coccidia from the Eimeria genus (Table 4). Most prevalent were eggs from the Trichuris genus and oocysts of Eimeria bovis, both at weekends and on weekdays. Eggs from the Trichostrongylidae family were observed only on weekdays. All five species of coccidia were observed together only at weekends, whereas on weekdays only three species were found. The prevalence of all parasites except Trichuris sp. was equal or higher at weekends than on weekdays (Table 4.). The level of parasitic infestation and vanamnesis did not indicate any clinical signs of disease. No correlations between parasitic burden and immunoreactive fecal cortisol level were found in either the direct or the shifted comparison with regard to Eimeria sp. $(\mathrm{r}=-0.038, \mathrm{P}=0.835$ for direct; $\mathrm{r}=-0.021, \mathrm{P}=0.921$ for shifted) and Trichuris sp.

Table 3 Effect of site and visitors on immunoreactive fecal cortisol level in European bison in a general linear mixed model

\begin{tabular}{lcccc}
\hline Source & B & SE & t & P \\
\hline Intercept & 4.16 & 0.54 & 7.73 & $<0.001^{*}$ \\
Sex (F) & 0.42 & 0.39 & 1.06 & 0.292 \\
Sex (M) & 0 & & & \\
Site (FCC Gołuchów) & -1.89 & 0.69 & -2.75 & 0.007 \\
Site (Poznań zoo) & -0.84 & 0.73 & -1.16 & 0.249 \\
Site (Warsaw zoo) & 0 & & & \\
Visitors (low) & 0.04 & 0.60 & 0.72 & 0.943 \\
Visitors (elevated) & 0 & & & \\
Site* visitors (Gołuchów, Low) & 2.59 & 0.88 & 2.93 & $0.005^{*}$ \\
Site* visitors (Poznań, Low) & -0.07 & 0.97 & 0.07 & 0.943 \\
Site*visitors (Warsaw, Low) & 0 & & & \\
\hline
\end{tabular}

Non-significant age was excluded in the selection procedure

*Statistically significant 


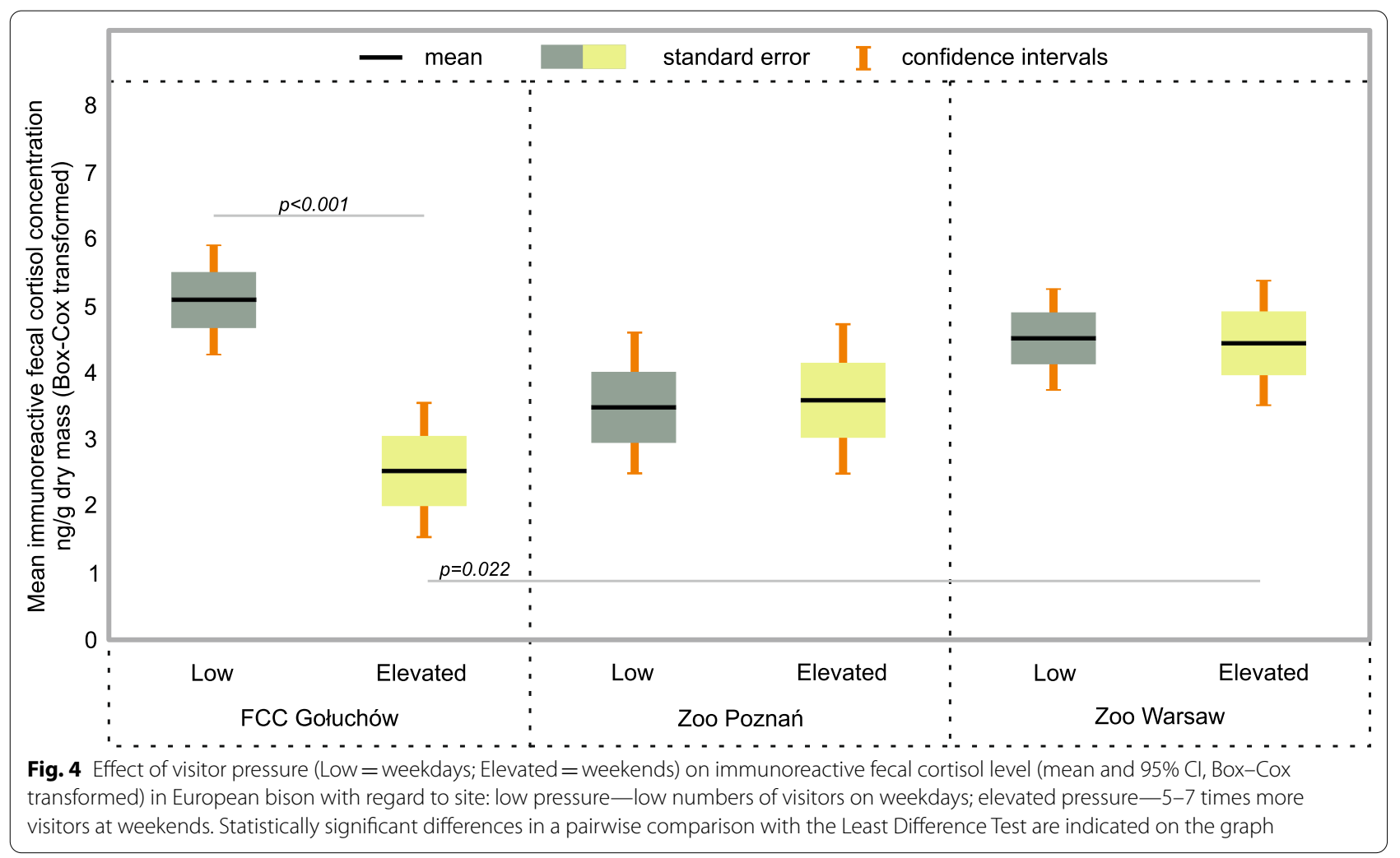

Table 4 Parasitic infestations of European bison at Warsaw Zoo during five days of fecal sampling

\begin{tabular}{|c|c|c|c|c|c|c|}
\hline \multirow[t]{3}{*}{ Parasite } & \multicolumn{3}{|l|}{ Weekdays } & \multicolumn{3}{|l|}{ Weekend } \\
\hline & \multirow[t]{2}{*}{ Prevalence (\%) } & \multicolumn{2}{|c|}{ Intensity (EPG/OPG) } & \multirow[t]{2}{*}{ Prevalence (\%) } & \multicolumn{2}{|c|}{ Intensity (EPG/OPG) } \\
\hline & & Range & Median & & Range & Median \\
\hline Trichostrongylidae & 14.29 & 50 & 50 & 0 & 0 & 0 \\
\hline Trichuris sp. & 31.75 & $200-2200$ & 550 & 35.71 & $50-1850$ & 300 \\
\hline Eimeria sp. & 52 & $50-300$ & 225 & 71 & $50-1770$ & 175 \\
\hline
\end{tabular}

EPG helminth eggs per gram of feces, OPG Eimeria oocysts per gram of feces

$(\mathrm{r}=-0.175, \mathrm{P}=0.329$ for direct $\mathrm{r}=0.148, \mathrm{P}=0.479$ for shifted).

\section{Discussion}

Breeding conditions and visitor pressure may affect immunoreactive fecal cortisol levels in captive European bison. Average immunoreactive fecal cortisol levels in the studied captive herds ranged from 7.45 to $17.23 \mathrm{ng} / \mathrm{g}$ dry fecal mass. Investigating immunoreactive fecal cortisol levels in a larger number of captive and wild European bison herds and identifying the main factors responsible for the increase in stress hormone levels could be a valuable contribution to the conservation efforts that are undertaken for this species. This is important because the results indicate that there may be significant differences in the welfare of captive European bison kept under different conditions.

The results show that the studied range of visitor pressure did not increase levels of immunoreactive fecal cortisol in these captive European bison. None of the examined bison herds displayed higher immunoreactive fecal cortisol level at weekends despite a fivefold-sevenfold increase in the number of visitors to their enclosures, thus indicating that visitor pressure (in the studied range) does not negatively affect the welfare of European bison. This result corresponds with other studies on captive ruminants (in zoo conditions), in which only a slight reaction to visitors was shown 
[24]. However, these results differ from those obtained for other some ungulates (Gazella soemmerringii, Bos gaurus, Cervus nippon and Antelope cervicapra), for which a negative response to increasing visitor pressure was found [20-23]. These discrepancies show that the response of captive wild animals to visitors can be species dependent $[16,50]$. Moreover, individual traits may also be of great importance in the welfare of captive animals [51] and may impact their reaction to visitors [15].

One should also remember to consider the season in which the study was conducted and the related limitations of the results. The study was conducted during a mild winter, and it is difficult to predict on this basis whether the same reaction would occur in a hot summer period with an exceptionally large number of visitors. The ambient temperature during material collection in the study ranged between 4 and $12{ }^{\circ} \mathrm{C}$. In Poland, the ambient temperature can exceed $35{ }^{\circ} \mathrm{C}$ in summer, and it can reach $-30{ }^{\circ} \mathrm{C}$ in winter [52]. The European bison is sensitive to high environmental temperatures $[6,53]$, which itself can probably cause physiological stress. Therefore, it is not possible to predict whether stimuli such as increased visitor pressure would have a greater physiological effect at high ambient temperatures. The lack of negative impact that was shown in this study occurred in moderate weather conditions and with moderate pressure from visitors.

The positive impact of visitors in Gołuchów indicates the role of local breeding conditions on the welfare of captive animals. This is probably the effect of social relations in the herd and, in particular, aggression between competing males. Competition between males in Gołuchów (in this case, between an 11-yearold male and a 3-year-old male) probably increased the stress levels of the whole herd. The differences observed between Gołuchów and Warsaw (in both these locations, the herds have a potentially conflictive social structure) show that more subtle factors than just the sex and age of the individuals in the herd may play an important role. The stress level could have been an individual effect. This phenomenon is indicated as an important element that affects animals' responses to breeding conditions [51,54-56]. The male in Gołuchów was considered aggressive when the herd structure had been disturbed, which may further increase conflict within the group; however, this does not explain why a positive reaction to visitors occurred only in Gołuchów and not in Warsaw, both of which are herds with a conflictive structure. The probable reason may be the feeding system and the arrangement of the enclosures in which the animals were kept. In Gołuchów, feeders with nutritious fodder and hay were located near visitors, and fodder was also offered in the afternoon when visitors were present. The increased pressure from visitors at weekends probably distracted the competing males in Gołuchów and reduced the frequency or intensity of their aggressive behavior. Aggression usually occurs around feeding areas, where the instinct to monopolize resources occurs [57-59]. In addition, the animal feeding system in Gołuchów meant that more intense competitive male behavior could take place not only during morning feeding but also in the afternoon. As cortisol metabolites are excreted via feces after a delay $[38,48,49]$, the possibility of finding elevated levels of immunoreactive fecal cortisol metabolites in Gołuchów was higher. This is important information when planning further research because it shows how many factors should be considered in order to correctly assess the welfare of the studied animals. If these suppositions are right, this could be another example of the positive impact of visitors on captive animals [14, 15, 18, 25], but it could also indicate the mitigating role of visitors in the social relations of captive animals as well as the importance of enclosure design and feeding systems.

The relationships between a herd's social structure and stress levels illustrate the "physiological cost" of maintaining such conflict-causing systems. In free-ranging populations, bulls can reach sexual maturity at 3 years of age, but generally this happens at four years [60]. At the age of three, young bulls begin to move between mixed groups (formed by adult and young cows), and from the age of four they form separate male 'bachelor' herds [61], thus indicating that the currently recommended [5] removal of subadult males from breeding herds is justified. Similar disruptive incidents caused by conflicts among social animals have been reported for other species kept in captivity [62]. In the case of the European bison, more research is needed to study this phenomenon more thoroughly in various social groups. Moreover, the arrangement of enclosures and even feeding systems may be important as in some situations these may allow the use of visitor pressure to mitigate potential conflicts in the herd. It should also be remembered that short-term stress cannot be treated as something definitely negative because increases in cortisol levels are a natural and necessary element that mobilizes the body to act in the event of disruptions in the environment [63]. However, long-term stress can have a negative impact on animals as it can disrupt many aspects of animal physiology, e.g., reproduction, immune response, or hormonal control of the metabolism [63-65]. Understanding and alleviating or eliminating the potential factors responsible for chronic stress could be very desirable in terms of protecting this species, both in breeding conditions and in the wild. 
Parasitic infections trigger the host's immune system, thus activating defensive mechanisms; they are also suspected to affect the release of glucocorticoids. However, the influence of parasites on the host's glucocorticoid level is still unclear as there are results that suggest both positive and negative correlations, or no relationship at all $[66,67]$. According to the latest findings, it is advised to correlate fecal glucocorticoid metabolite levels with other factors such as the host's age, sex and reproductive status, but also parasite type, infestation severity, food availability or social stressors [67]. Moreover, in an experimental infection of reindeer with gastrointestinal nematodes and subsequent parasitological treatment, it turned out that both infected and treated reindeer had similar levels of fecal glucocorticoid metabolites [68]. The authors suggested that these results could be explained by the tolerance strategy used by the host to cope with infestation. In our study, we found no correlation between parasite infestation and glucocorticoid levels, but this could be due to the low level of the parasite infestation. A host organism with a low parasite burden may be able to tackle the infestation with one of three protective strategies: avoidance, resistance or tolerance [69].

Other limitations of the study should be also pointed out. The exact delay between cortisol circulation in the blood and excretion into feces is not known for the European bison. Some studies indicate a high inter-individual variability in such delays (e.g., [70]), which could also have impacted our results. Our study would have been strengthened by including behavioral observations and more precise visitor numbers.

\section{Conclusions}

The study determined immunoreactive fecal cortisol levels in various captive herds of European bison. Moderate visitor pressure did not increase the stress levels of the studied animals. However, we found that the increased presence of visitors probably modified the social relations in a herd in a positive way. More subtle factors, such as individual animal characteristics, feeding systems, and the arrangement of enclosures, can be of great importance in terms of the effect of visitors on animals. The results can be used in guidelines for the management of European bison populations. Nevertheless, further research is needed to better understand the stress reactions of European bison in different seasons (thermal conditions), with different social structures of herds, with varying visitor pressure, and with behavioral observations. Additional investigation is also needed concerning the relation between parasite infestation and stress levels in European bison; however, this should be performed on animals whose infestation levels are more varied.

\section{Supplementary Information}

The online version contains supplementary material available at https://doi. org/10.1186/s13028-021-00589-9.

Additional file 1: Table S1. Ranking of the models (including null model) explaining the immunoreactive fecal cortisol level in European bison ( $\triangle \mathrm{AIC}$-AIC differences, $\omega_{\mathrm{i}}$-Akaike weights, Rank_rank of the models based on AIC values, SITE-location (Poznań, Warsaw or Gołuchów); VISITORS - visitor pressure (low and elevated number of visitors), AGEage of animals, SEX — sex of animals); bolded text in a row indicates the chosen model.

\section{Acknowledgements}

We would like to thank the administrations of Zoo Warsaw, Poznan Zoo and the Forest Culture Center in Gołuchów for allowing us to conduct the study. For their invaluable help with organizing the fieldwork, we thank Sylwia Gródkowska and Adam Banaszek from Warsaw Zoo, Jarosław Przybylski from Poznań Zoo, and Stanisław Czołnik and Tomasz Rakowski from FCC Gołuchów. We also thank Magdalena Supińska, Elżbieta Sendecka, and Yvonne Kemp for their help with material sampling.

\section{Prior publication}

Data have not been published previously.

\section{Authors' contributions}

DK participated in methodology elaboration, provision of resources, laboratory and statistical analysis, visualization, original draft preparation and supervision. RŁ participated in methodology elaboration, laboratory analysis and original draft preparation. MG participated in methodology elaboration, provision of resources, laboratory analysis and original draft preparation. AŚ participated in methodology elaboration, laboratory analysis and review and editing of the original draft. DG participated in methodology elaboration, laboratory analysis, review and editing of the original draft. RB participated in methodology elaboration, provision of resources, laboratory analysis, review and editing of the original draft. BK participated in methodology elaboration, provision of resources, laboratory analysis, review and editing of the original draft. TK participated in original draft preparation. WO participated in provision of resources, review and editing of the original draft, funding acquisition and supervision. All authors read and approved the final manuscript.

\section{Funding}

This research was funded by the Forest Fund, Poland in frame of "Complex project of European bison conservation by State Forests" (Contract No. OR.271.3.10.2017). A funding body was not involved in design, collection of samples, analyses, interpretation and writing of the manuscript. The equipment marked with * were purchased as part of the Project entitled: "Building of the Centre of Interdisciplinary Research" realized as part of the Operational Programme "Development of Eastern Poland" 2007-2013, Priority l: Modern Economy, Action 1.3. The Advancement of Innovation, co-financed by the European Regional Development Fund.

\section{Availability of data and materials}

The datasets used and/or analysed during the current study are available from the corresponding author on reasonable request.

\section{Declarations}

\section{Ethics approval and consent to participate}

This study did not require official or institutional ethical approval. The animals were handled according to high ethical standards and national legislation.

\section{Consent for publication}

Not applicable.

\section{Competing interests}

The authors declare that they have no competing interests. 


\section{Author details}

'Department of Animal Genetics and Conservation, Institute of Animal Sciences, Warsaw University of Life Sciences, Ciszewskiego 8, 02-786 Warsaw, Poland. ${ }^{2}$ Centre for Interdisciplinary Research, The John Paul II Catholic University of Lublin, Konstantynów 1J, 20-708 Lublin, Poland. ${ }^{3}$ Department of Food Hygiene and Public Health Protection, Institute of Veterinary Medicine, Warsaw University of Life Sciences, Nowoursynowska 159, 02-776 Warsaw, Poland. ${ }^{4}$ Warsaw Zoological Garden, Ratuszowa 1/3, 03-461 Warsaw, Poland. ${ }^{5}$ Laboratory of Oxidative Stress, Centre for Interdisciplinary Research, The John Paul II Catholic University of Lublin, Konstantynów 1J, 20-708 Lublin, Poland. ${ }^{6}$ Department of Chemistry, Institute of Food Sciences, Warsaw University of Life Sciences (SGGW), Nowoursynowska 159 C, 02-776 Warsaw, Poland. ${ }^{7}$ Department of Food Technology and Assessment, Institute of Food Sciences, Warsaw University of Life Sciences (SGGW), Nowoursynowska 159 C, 02-776 Warsaw, Poland.

\section{Received: 27 July 2020 Accepted: 3 June 2021}

Published online: 10 June 2021

\section{References}

1. Pucek Z, Belousova IP, Krasińska M, Krasiński ZA, Olech W. European bison: status survey and conservation action plan. IUCN/SSC Bison Specialist Group. IUCN, Gland, Switzerland and Cambridge, UK. 2004.

2. Olech W, Perzanowski K. Changes of size and structure of world population of European bison in years 2000-2015. In: European Bison Conservation Newsletter. 2016; 9:5-10.

3. Raczyński J. European Bison pedigree book 2017. Białowieża: Białowieża National Park: 2018. p. 1-85.

4. Olech W, Klich D, Perzanowski K. Development of a new action plan for the European bison. Oryx. 2019;53:214. https://doi.org/10.1017/S0030 605318001369

5. Olech W, Perzanowski K. Best practices manual for protection of European Bison. Warsaw: coordination center for environmental projects. 2014.

6. Kaczmarek-Okrój M, Bruczyńska M, Wojciechowska M, Klich D, Głowacz K, Gajewska K, Olech W. Rules of capture and transport of wisents from Poland to other European countries. In: European Bison Conservation Newsletter. 2016;9:71-86.

7. Olech W, Perzanowski K. A genetic background for reintroduction program of the European bison (Bison bonasus) in the Carpathians. Biol Conserv. 2002;108:221-8.

8. Olech W, Perzanowski K. Supplementation of genetic structure through introductions of selected animals ex situ into free ranging wisent population of Bieszczady Mountains. In: European Bison Conservation Newsletter. 2016: 9:23-30

9. Larska M, Krzysiak MK. Infectious disease monitoring of European bison (Bison bonasus). In: Ferretti M, editor. Wildlife population monitoring London: IntechOpen; 2019. https://doi.org/10.5772/intechopen.84290.

10. Klich D, Łopucki R, Stachniuk A, Sporek M, Fornal E, Wojciechowska M, Olech W. Pesticides and conservation of large ungulates: health risk to European bison from plant protection products as a result of crop depredation. PLoS ONE. 2020;15:e0228243. https://doi.org/10.1371/journ al.pone.0228243.

11. Klich D, Olech W, Łopucki R, Danik K. Community attitudes to the European bison Bison bonasus in areas where its reintroduction is planned and in areas with existing populations in northeastern Poland. Eur J Wildl Res. 2018:64:61. https://doi.org/10.1007/s10344-018-1219-5.

12. SamojlikT. Bison in art within the centuries. In: Wolfram KB, editor. An European bison extermination and rescue. Supraśl: Uroczysko; 2005. p. $75-6$

13. Sztych D. Culture-forming role of the European bison. In: European Bison Conservation Newsletter. 2008; 1:161-90.

14. Shepherdson DJ, Carlstead KC, Wielebnowski N. Cross-institutional assessment of stress responses in zoo animals using longitudinal monitoring of faecal corticoids and behaviour. Anim Welfare. 2004;13:105-14.

15. Sherwen SL, Hemsworth PH. The visitor effect on zoo animals: implications and opportunities for zoo animal welfare. Animals. 2019;9:366. https://doi.org/10.3390/ani9060366.
16. Mason GJ. Species differences in responses to captivity: stress, welfare and the comparative method. Trends Ecol Evol. 2010;25:713-21. https:// doi.org/10.1016/j.tree.2010.08.011.

17. Morgan K, Tromborg C. Sources of stress in captivity. Appl Anim Behav Sci. 2007;102:262-302. https://doi.org/10.1016/j.applanim.2006.05.032.

18. Sade C. Visitor effects on zoo animals. The Plymouth Student Scientist. 2013;6:423-33.

19. Farrand A. The effect of zoo visitors on the behaviour and welfare of zoo mammals. PhD thesis. Striling University. 2008.

20. Mansour AA, Zakaria AH, Fraser AF. Effect of enclosure quality on reactivity and welfare of captive Soemmerring's gazelle (Gazella soemmerringii). J Appl Anim Welf Sci. 2000;3:335-43. https://doi.org/10.1207/S15327604J AWS0304 5.

21. Sekar M, Rajagopal T, Archunan G. Influence of zoo visitor presence on the behavior of captive Indian gaur (Bos gaurus gaurus) in a zoological park. J Appl Anim Welf Sci. 2008;11:352-7. https://doi.org/10.1080/10888 700802330093

22. Shen-in L, Todd PA, Yan Y, Lin Y, Hongmei F, Wan-Hong W. The effects of visitor density on sika deer (Cervus nippon) behaviour in Zhu-Yu-Wan Park. China Anim Welfare. 2010:19:61-5.

23. Rajagopal T, Archunan G, Sekar M. Impact of zoo visitors on the fecal cortisol levels and behavior of an endangered species: Indian blackbuck (Antelope cervicapra L.). J Appl Anim Welf Sci. 2011;14:18-32. https://doi. org/10.1080/10888705.2011.527598.

24. Thompson V. Behavioral response of 12 ungulate species in captivity to the presence in humans. Zoo Biol. 1989;8:275-97. https://doi.org/10 1002/zoo.1430080308.

25. Eltorai AEM, Sussman RW. The "visitor effect" and captive black-tailed prairie dog behavior. Zool Gärt. 2010;79:109-20. https://doi.org/10.1016/j. zoolgart.2010.07.002

26. Wood W. Interactions among environmental enrichment, viewing crowds, and zoo chimpanzees (Pantroglodytes). Zoo Biol. 1998;17:211-30. https://doi.org/10.1002/(SICI)1098-2361(1998)17:3\%3c211::AID-ZOO5\% 3e3.0.CO;2-C

27. Owen C. Do visitors affect the Asian short-clawed otter in a captive environment? Proceedings of the sixth annual symposium on zoo research BIAZA, London. 2004. p. 202-11.

28. Ramos A, Manizan L, Rodriguez E, Kemp YJ, Sueur C. The social network structure of a semi-free roaming European bison herd (Bison bonasus). Behav Process. 2019;158:97-105. https://doi.org/10.1016/j.beproc.2018. 11.005

29. Ramos A, Petit O, Longour P, Pasquaretta C, Sueur C. Collective decisionmaking during group movements in European bison, Bison bonasus. Anim Behav. 2015;109:149-60

30. Krasińska M, Krasiński Z. European bison: the nature monograph. Poland: Springer; 2013.

31. Haidt A, Kamiński T, Borowik T, Kowalczyk R. Human and the beast-flight and aggressive responses of European bison to human disturbance. PLoS ONE. 2018;13:e0200635. https://doi.org/10.1371/journal.pone.0200635.

32. Millspaugh JJ, Washburn BE. Use of fecal glucocorticoid metabolite measures in conservation biology research: considerations for application and interpretation. Gen Comp Endocr. 2004;138:89-199. https://doi.org/ 10.1016/j.ygcen.2004.07.002.

33. Palme R. Non-invasive measurement of glucocorticoids: advances and problems. Physiol Behav. 2019;199:229-43. https://doi.org/10.1016/j. physbeh.2018.11.021.

34. Fureix C, Benhajali H, Henry S, Bruchet A, Prunier A, Ezzaouia M, et al. Plasma cortisol and faecal cortisol metabolites concentrations in stereotypic and non-stereotypic horses: do stereotypic horses cope better with poor environmental conditions? BMC Vet Res. 2013;9:3. https://doi.org/ 10.1186/1746-6148-9-3

35. Pyziel AM, Jóźwikowski M, Demiaszkiewicz AW. Coccidia (Apicomplexa: Eimeriidae) of the lowland European bison Bison bonasus (L.). Vet Parasitol. 2014;202:138-44. https://doi.org/10.1016/j.vetpar.2014.03.014.

36. Fleming MW. Cortisol as an indicator of severity of parasitic infections of Haemonchus contortus in lambs (Ovis aries). Comp Biochem Phys B. 1997;116:41-4. https://doi.org/10.1016/S0305-0491(96)00157-5.

37. St. Juliana JR, Khokhlova IS, Wielebnowski N, Kotler BP, Krasnov BR. Ectoparasitism and stress hormones: strategy of host exploitation, common host-parasite history and energetics matter. J Anim Ecol. 2014;83:1113-23. https://doi.org/10.1111/1365-2656.12217. 
38. Pyziel AM, Demiaszkiewicz AW, Klich D, Laskowski Z. A morphological and molecular comparison of Eimeria bovis-like oocysts (Apicomplexa: Eimeriidae) from European bison, Bison bonasus L., and cattle, Bos taurus L., and the development of two multiplex PCR assays for their identification. Vet Parasitol. 2019. https://doi.org/10.1016/j.vetpar.2019.08.011.

39. Karbowiak G, Demiaszkiewicz AW, Pyziel AM, Wita I, Moskwa B, Werszko J, Bień J, Goździk K, Lachowicz J, Cabaj W. The parasitic fauna of the European bison (Bison bonasus) (Linnaeus, 1758) and their impact on the conservation. Part 1. The summarizing list of parasites noted. Acta Parasitol. 2014;59:363-71. https://doi.org/10.2478/s1 1686-014-0252-0.

40. Millspaugh JJ, Woods RJ, Hunt KE, Raedeke KJ, Brundige GC, Washburn BE, Wasser SK. Fecal glucocorticoid assays and the physiological stress response in elk. Wildl Soc Bull. 2001;29:899-907. https://doi.org/10.2307/ 3784417.

41. Pavitt AT, Pemberton JM, Kruuk LE, Walling CA. Testosterone and cortisol concentrations vary with reproductive status in wild female red deer. Ecol Evol. 2016;6:1163-72. https://doi.org/10.1002/ece3.1945.

42. Santos JP, Acevedo P, Carvalho J, Queirós J, Villamuelas M, Fonseca C, Gortázar C, López-Olvera JR, Vicente J. The importance of intrinsic traits, environment and human activities in modulating stress levels in a wild ungulate. Ecol Indic. 2018;89:706-15. https://doi.org/10.1016/j.ecolind. 2018.02.047.

43. Klich D, Łopucki R, Ścibior A, Gołębiowska D, Wojciechowska M. Roe deer stress response to a wind farms: methodological and practical implications. Ecol Indic. 2020;117:106658. https://doi.org/10.1016/j.ecolind.2020. 106658.

44. Taylor MA, Coop RL, Wall RL. The laboratory diagnosis of parasitism. In: Taylor MA, Coop RL, Wall RL, editors. Veterinary parasitology. Oxford: Blackwell Publishing; 2007. p. 798-9.

45. Pyziel AM, Demiaszkiewicz AW. Coccidia (Apicomplexa:Eimeriidae) of elk (Alces alces) in Poland. Parasitol Res. 2013;112:2083-5. https://doi.org/10. 1007/s00436-012-3262-6.

46. Duszynski DW, Wilber PG. A guideline for the preparation of species description in the Eimeriidea. J Parasitol. 1997;83:333-6. https://doi.org/ $10.2307 / 3284470$.

47. Mostl E, Messmann S, Bagu E, Robia C, Palme R. Measurement of glucocorticoid metabolite concentrations in faeces of domestic livestock. Zentralbl Veterinarmed A. 1999;46:621-31.

48. Pawluski J, Jego P, Henry S, Bruchet A, Palme R, Coste C, Hausberger M. Low plasma cortisol and fecal cortisol metabolite measures as indicators of compromised welfare in domestic horses (Equus caballus). PLOS ONE. 2017;12:e0182257. https://doi.org/10.1371/journal.pone.0182257.

49. Burnham KP, Anderson DR. Model selection and multimodel inference: a practical information-theoretic approach. 2nd ed. New York: Springer; 2002.

50. Queiroz MB, Young RJ. The different physical and behavioural characteristics of zoo mammals that influence their response to visitors. Animals. 2018;8:139. https://doi.org/10.3390/ani8080139.

51. Hill SP, Broom DM. Measuring zoo animal welfare: theory and practice. Zoo Biol. 2009;28:531-44. https://doi.org/10.1002/zoo.20276.

52. Tomczyk AM, Bednorz E, Półrolniczak M, Kolendowicz L. Strong heat and cold waves in Poland in relation with the large-scale atmospheric circulation. Theor Appl Climatol. 2019;137:1909-23. https://doi.org/10.2478/ v10145-012-0010-1.

53. Pape SB. Identifying trends of thermoregulating behaviour in European bison within the Kraansvlak Pilot Project. Bachelor's thesis. Utrecht University. 2015

54. Palme R. Monitoring stress hormone metabolites as a useful, non-invasive tool for welfare assessment in farm animals. Anim Welf. 2012;21:331. https://doi.org/10.7120/09627286.21.3.331.

55. Stubsjøen SM, Bohlin J, Dahl E, Knappe-Poindecker M, Fjeldaas T, Lepschy M, Palme R, Langbeine J, Ropstad E. Assessment of chronic stress in sheep (part I): the use of cortisol and cortisone in hair as non-invasive biological markers. Small Ruminant Res. 2015;132:25-31. https://doi.org/ 10.1016/j.smallrumres.2015.09.015.

56. Godyń D, Nowicki J, Herbut P. Effects of environmental enrichment on pig welfare_a review. Animals. 2019;9:383. https://doi.org/10.3390/ani90 60383.

57. Cassinello J. Food access in captive Ammotragus: the role played by hierarchy and mother-infant interactions. Zoo Biol. 2002;21:597-605. https:// doi.org/10.1002/zoo.10062.

58. DeVries TJ, Von Keyserlingk MAG, Weary DM. Effect of feeding space on the inter-cow distance, aggression, and feeding behavior of free-stall housed lactating dairy cows. J Dairy Sci. 2004. https://doi.org/10.3168/jds. S0022-0302(04)73293-2.

59. Mui NT, Ledin I. Effect of group size on feed intake, aggressive behaviour and growth rate in goat kids and lambs. Small Ruminant Res. 2007;72:187-96. https://doi.org/10.1016/j.smallrumres.2006.10.010.

60. Czykier E, Sawicki B, Krasinska M. Postnatal development of the European bison spermatogenesis. Acta Theriol. 1999:44:77-90.

61. Krasińska M, Krasiński Z. Bisoniana 112. Composition, group size, and spatial distribution of European bison bulls in Białowieża forest. Acta Theriol. 1995;1995(40):1-21.

62. Kleiman DG, Thompson KV, Baer CK. Wild mammals in captivity: principles and techniques for zoo management. 2nd ed. Chicago: University of Chicago Press; 2010. https://doi.org/10.1111/aec.12096.

63. Moberg GP. Biological response to stress: implications for animal welfare. In: Moberg GP, Mench JA, editors. The biology of animal stress basic principles and implications for animal welfare. London: CABI Publishing; 2000. p. 1-21. https://doi.org/10.1079/9780851993591.0001.

64. Charmandari E, Tsigos C, Chrousos G. Endocrinology of the stress response. Annu Rev Physiol. 2005;67:259-84. https://doi.org/10.1146/ annurev.physiol.67.040403.120816.

65. Glaser R, Kiecolt-Glaser JK. Stress-induced immune dysfunction: implications for health. Nat Rev Immunol. 2005;5:243-51. https://doi.org/10. 1038/nri1571.

66. O'Dwyer K, Dargent F, Forbes MR, Koprivnikar J. Parasite infection leads to widespread glucocorticoid hormone increases in vertebrate hosts: a meta-analysis. J Anim Ecol. 2020;89:519-29. https://doi.org/10.1111/ 1365-2656.13123.

67. Defolie C, Merkling T, Fichtel C. Patterns and variation in the mammal parasite-glucocorticoid relationship. Biol Rev. 2020;95:74-93. https://doi. org/10.1111/brv.12555.

68. Carlsson AM, Mastromonaco G, Vandervalk E, Kutz S. Parasites, stress and reindeer: infection with abomasal nematodes is not associated with elevated glucocorticoid levels in hair or faeces. Conserv Physiol. 2016;1:4. https://doi.org/10.1093/conphys/cow058.

69. Medzhitov R, Schneider DS, Soares MP. Disease tolerance as a defense strategy. Science. 2012;24(335):936-41. https://doi.org/10.1126/science. 1214935.

70. Navarro-Castilla Á, Garrido M, Hawlena H, Barja I. Non-invasive monitoring of adrenocortical activity in three sympatric desert gerbil species. Animals. 2021;11(1):75. https://doi.org/10.3390/ani11010075.

\section{Publisher's Note}

Springer Nature remains neutral with regard to jurisdictional claims in published maps and institutional affiliations. 